\title{
ELABORAÇÃO E CARACTERIZAÇÃO DE LEITE DE BÚFALA FERMENTADO COM ABACAXI EM CALDA
}

\section{Elaboration and characterization of fermented buffalo milk with pineapple in syrup}

\begin{abstract}
Taís Helena Gouveia Rodrigues ${ }^{1^{*},}$ Állyda Suennya dos Santos Paraibano ${ }^{1}$, Luana Gabrielle
\end{abstract} Tavares dos Santos ${ }^{1}$, Ricardo Alexandre Silva Pessoa ${ }^{2}$, Silvana Gonçalves Brito de Arruda ${ }^{1}$

\section{RESUMO}

A bubalinocultura é uma atividade de inclinação crescente no Brasil, destacando o leite de búfala que difere dos demais leites por conter maiores teores de nutrientes dentre outros. O estudo objetivou desenvolver e analisar leites fermentados elaborados a partir do leite de búfala (LB) com a adição de abacaxi em calda, em diferentes proporções em relação ao leite de vaca (LV) (formulação P com 100\% LV, F1 com $50 \% \mathrm{LB} / 50 \% \mathrm{LV}$, e F2 com $100 \% \mathrm{LB}$ ). As formulações foram submetidas a análises microbiológicas (coliformes a $45^{\circ} \mathrm{C}$ e Salmonella sp.), análises físico-químicas ( $\mathrm{pH}$, acidez em ácido lático, cinzas, gordura, proteínas, umidade e carboidratos por diferença) e análise sensorial por meio de testes afetivos com 120 indivíduos. As análises físico-químicas e sensoriais foram submetidas a análise de variância (ANOVA) seguida do teste de Tukey $(p \leq 0,05)$. Todas as formulações estiveram dentro dos padrões microbiológicos exigidos pela legislação. Os valores de $\mathrm{pH}$ para todas as amostras variaram de 4,1 a 4,3 sem diferença de acidez. A F2 apresentou maior percentual de gordura e proteína. Para teor de cinzas e umidade não houve diferença entre as formulações e as formulações P e F1 apresentaram maior teor de carboidratos. A F2 apresentou bom índice de aceitabilidade para todos os atributos na análise sensorial, sendo a amostra preferida. O leite de búfala fermentado com a adição de abacaxi em calda torna-se uma alternativa viável de produto para a indústria láctea do ponto de vista sensorial/afetivo, nutricional e econômico.

Palavras-chave: análise sensorial; novos produtos lácteos; produção leiteira de búfalas.

1 Universidade Federal de Pernambuco, Centro Acadêmico de Vitória, Rua Alto do Reservatório, s/n, Bela Vista, 55608-680, Vitória de Santo Antão, PE, Brasil. E-mail: taishgrodrigues@gmail.com

2 Universidade Federal Rural de Pernambuco, Departamento de Zootecnia, Recife, PE, Brasil.

* Autor para correspondência

Recebido / Received: 29/08/2019

Aprovado / Approved: 21/06/2020 


\begin{abstract}
Bubalinoculture is an activity of increasing inclination in Brazil, with emphasis on buffalo milk, which differs from other kinds of milk because it contains higher levels of nutrients, among others. The study aimed to develop and analyze fermented milk made from buffalo milk (BM) with addition of pineapple in the syrup, in different proportions in relation to cow's milk $(\mathrm{CM})$ (formulation $\mathrm{P}$ with $100 \% \mathrm{CM}$, F1 with $50 \% \mathrm{BM} / 50 \% \mathrm{CM}$, and $\mathrm{F} 2$ with $100 \% \mathrm{BM}$ ). The formulations were subjected to microbiological analysis (coliforms at $45^{\circ} \mathrm{C}$ and Salmonella sp.), physical-chemical analyzes $(\mathrm{pH}$, acidity in lactic acid, ash, fat, proteins, moisture, and carbohydrates by difference) and sensory analyzes through affective tests with 120 individuals. The physical-chemical and sensory analyzes were submitted to analysis of variance (ANOVA) followed by the Tukey test $(\mathrm{p} \leq 0.05)$. All formulations are within the microbiological standards required by legislation. The $\mathrm{pH}$ values for all samples ranged from 4.1 to 4.3 with no difference in acidity. F2 showed a higher percentage of fat and protein. For ash and moisture content, there was no difference between the formulations, and the $\mathrm{P}$ and $\mathrm{F} 1$ formulations showed a higher carbohydrate content. F2 showed a good acceptability index for all attributes in the sensory analysis, being the preferred sample. Fermented buffalo milk with the addition of pineapple in syrup becomes a viable alternative product for the dairy industry from a sensory/affective, nutritional, and economic point of view.
\end{abstract}

Keywords: sensory analysis; new dairy products; buffalo milk production.

\section{INTRODUÇ̃̃̃O}

A bubalinocultura é uma atividade de inclinação crescente em todo o Brasil, desde sua chegada em 1985 até os tempos atuais. Isto deu-se principalmente por suas caraterísticas de ser facilmente adaptável aos diversos tipos de ambiente, considerável fertilidade, e por ter uma longevidade produtiva. Foram inicialmente ocupando o cenário pecuário de corte em diversas regiões do país, logo em seguida foram observadas outras características bubalinas com potencial de exploração, como por exemplo para leite (BERNARDES, 2007; COELHO, 2019).

Assim, dentre todas as aptidões produtivas dos búfalos, a produção leiteira vem ganhando destaque (GUIMARÃES et al., 2015). Segundo a FAO (2013), no coorte de 2009 - 2012 observa-se que, em termos de produção leiteira de animais, o leite de búfala já se apresentava em segundo lugar no ranking mundial. Mais recentemente, Vieira et al. (2018) concluíram que a produção de leite de búfalas é superior a somatória da produção de cabras, ovelhas e camelas.

O leite de búfala (LB) difere dos demais tipos de leite existentes, pois contêm maiores teores de proteína, gordura, minerais como o cálcio e fósforo, bem como alto teor de lactose, cinzas e acidez (MACEDO et al., 2001; ANDRIGHETTO, 2011). Outras características marcantes do LB são: a sua coloração totalmente branca, devido à ausência de pigmentos carotenoides, o que também confere coloração branca e o sabor levemente adocicado a produtos alimentícios oriundos dele, como por exemplo o leite fermentado (ANDRADE et al., 2011).

Os leites fermentados têm como propriedade principal a ação de um ou vários cultivos para serem produzidos, como 
Lactobacillus acidophilus, Lactobacillus casei, Bifidobacterium sp., Streptococus salivarius subsp thermophilus e/ou outras bactérias ácido-láticas que contribuem com características do produto (MAZIERO et al., 2011). Produtos elaborados com estas bactérias possuem grande valor nutricional e boa aceitação, sendo incluído na rotina diária por ser prático e de fácil consumo, considerado uma ótima fonte de vitaminas e minerais, e constituem veículos em potencial para probióticos (GUIMARÃES et al., 2015). Assim, produtos lácteos produzidos a partir do LB ocupam colocação de destaque por apresentar características sensoriais, nutricionais e físico-químicas diferentes dos produtos produzidos exclusivamente de leite de vaca (MODESTO JÚNIOR et al., 2016). A adição de frutas ao leite fermentado tem sido alvo de testes por uma maior aceitação popular e despertado o interesse de indústrias alimentícias nacionais (OLIVEIRA et al., 2011).

Sob essa ótica, identifica-se a carência de estudos que realizem associação entre leite fermentado e frutas típicas regionais a fim de aproveitar de forma integral o potencial de mercado regional (MARINHO et al., 2012). Dentre estas, destaca-se o abacaxi, advinda do abacaxizeiro, que é uma planta tropical originária de regiões de clima quente e seco ou com chuvas irregulares, sendo o Norte, o Nordeste e o Sudeste os maiores produtores do país (MATOS et al., 2006). O abacaxi possui boas condições nutricionais, rico em vitaminas e minerais e características de sabor e aroma como um bom equilíbrio entre o ácido e o doce (SEBRAE, 2016).

O desenvolvimento de leite de búfala fermentado combinado com o abacaxi em calda pode constituir uma inovação tecnológica, visando melhorar as características e agregar valor a ambas as matérias-primas. Assim, o presente trabalho propôs desenvolver leite de búfala fermentado com abacaxi em calda em diferentes proporções, e posteriormente avaliar seus parâmetros microbiológicos e características físico-químicas, em conjunto com a análise sensorial dos produtos desenvolvidos.

\section{MATERIAIS E MÉTODOS}

Esta pesquisa caracteriza-se como científica, laboratorial, quantitativa e discriminativa. Foi desenvolvida nos laboratórios de Técnica Dietética/Análise Sensorial de Alimentos, Bromatologia e Microbiologia da Universidade Federal de Pernambuco (UFPE) - Centro Acadêmico de Vitória de Santo Antão (CAV).

O leite adquirido para esta pesquisa foi obtido através da ordenha em búfalas leiteiras pertencentes à raça Murrah, no Município de Taipu, RN, na fazenda Tapuio, transportado em caixa térmica, sob controle de temperatura até o Laboratório de Técnica Dietética da UFPE, para o seu processamento e realização das análises físico-químicas.

A presente pesquisa foi submetida e aprovada pelo Comitê de Ética em Pesquisa do Centro de Ciências da Saúde da UFPE, CAAE 93576318.3.0000.5208, em atendimento às normas regulamentadoras de Pesquisa envolvendo seres humanos - Resolução 466/2012, do Conselho Nacional de Saúde. Após aprovação, procedeu-se com a realização das análises microbiológicas, físico-químicas e sensoriais.

Foram elaboradas e testadas três formulações de leite fermentado contendo distintas proporções de leite de búfala e leite de vaca (Tabela 1), com 10\% de abacaxi em calda em cada.

\section{Elaboração do leite fermentado}

O processamento do leite fermentado (Figura 1) seguiu as etapas de: aquisição dos leites, tratamento térmico sob a 
temperatura de $90{ }^{\circ} \mathrm{C}$ durante 10 minutos, resfriamento a $43{ }^{\circ} \mathrm{C}$, adição de cultura láctea da marca Bio Rich $^{\circledR}$ (contém culturas de L. acidophilus LA-5, Bifidobacterium BB-12 e $S$. thermophilus) na concentração 1 $\mathrm{g} / \mathrm{L}$, armazenamento sob temperatura de 45 ${ }^{\circ} \mathrm{C}$ até que ocorra a fermentação. $\mathrm{O}$ tempo médio necessário para a fermentação foi de 6 horas. Após a fermentação, o iogurte foi colocado sob refrigeração a $4{ }^{\circ} \mathrm{C}$ e em seguida homogeneizado e adicionado de calda de abacaxi, estando assim, pronto para o consumo.

\section{Elaboração do abacaxi em calda}

Para a obtenção do abacaxi em calda, foram selecionados abacaxis do tipo Pérola adquiridos em uma feira livre na cidade de Vitória de Santo Antão, PE. Em seguida foram sanitizados, descascados, cortados em pequenos cubos e levados a cocção, junto a
$10 \%$ de açúcar (peso/volume) e a água por pelo menos 40 minutos. O fim do processo se deu quando a calda atingiu o teor de sólidos solúveis de $22^{\circ}$ Brix. Esperou-se esfriar até a temperatura ambiente, para que houvesse a adição às formulações de leite fermentado. A Figura 2 expressa o fluxograma para obtenção do abacaxi em calda.

\section{Análises microbiológicas}

Foram realizadas análises microbiológicas para coliformes a $45^{\circ} \mathrm{C}$ e Salmonella sp. conforme o que preconiza a Legislação Brasileira de Padrão Microbiológico para alimentos da Resolução da Diretoria Colegiada (RDC) $\mathrm{n}^{\mathbf{0}} 12 / 2001 \mathrm{da}$ Agência Nacional de vigilância Sanitária (ANVISA) (BRASIL, 2001).

Para coliformes a $45{ }^{\circ} \mathrm{C}$ foi realizada determinação do Número Mais Provável (NMP) de coliformes, usando o meio de

Tabela 1 - Percentual de variação das formulações de leite fermentado a partir do leite de búfala e de vaca

\begin{tabular}{lccc}
\hline Ingredientes/Formulações & P \% & F1 \% & F2 \% \\
\hline Leite de búfala & 0,0 & 50 & 100 \\
Leite de vaca & 100 & 50 & 0,0 \\
\hline
\end{tabular}

P\% - Formulação Padrão com 100\% leite de vaca; F1\% - Formulação 1 com 50\% de leite de búfala e 50\% de leite de vaca; F2\% - Formulação com 100\% leite de búfala.

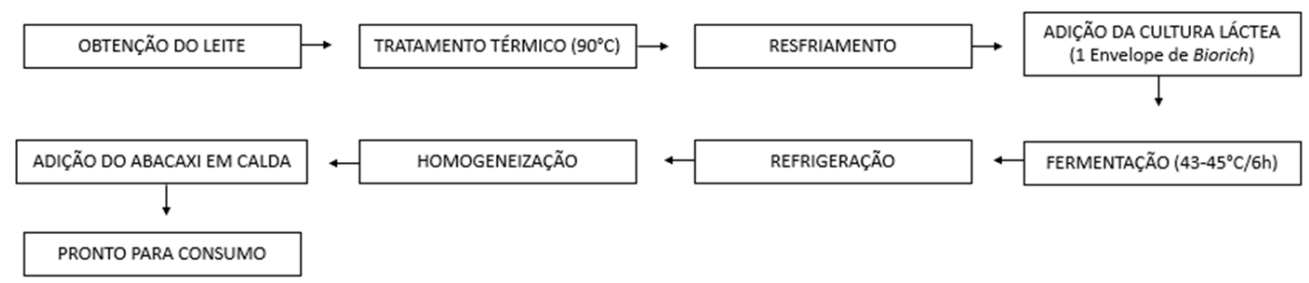

Figura 1 - Fluxograma representativo das etapas para obtenção das formulações de leite fermentado com abacaxi em calda 
cultura caldo lactosado verde bile brilhante $2 \%$ através da técnica de tubos múltiplos. $\mathrm{Na}$ verificação de Salmonella sp., uma porção de $25 \mathrm{~g}$ da amostra foi contida em água salina peptonada e incubada a $35^{\circ} \mathrm{C}$ por 24 horas. Após incubação, alíquotas de $0,1 \mathrm{~mL}$ da amostra em solução salina foi transferido para placa de Petri, as quais foram encubadas sob temperatura de $35^{\circ} \mathrm{C}$ por um período de 24 horas.

\section{Análises físico-químicas}

Por possuir pedaços pequenos do abacaxi, primeiramente as formulações foram trituradas a partir de um gral de porcelana de capacidade $100 \mathrm{ml}$, em seguida homogeneizadas com um bastão de vidro. Realizadas em triplicata, foram feitas análises de acidez em ácido lático, resíduo por incineração (cinzas), umidade, gordura, proteínas, carboidratos e $\mathrm{pH}$.

Para acidez em ácido lático foi utilizado o método do potenciômetro para leites fermentados (método 493/IV; ZENEBON et al., 2008). O conteúdo de cinzas foi analisado através da carbonização segundo o método 31.1.04 da AOAC (CUNNIFF, 1995). Determinou-se o teor de umidade de acordo com o método 31.1.02 da AOAC (CUNNIFF, 1995). A gordura foi determinada a partir do butirômetro de Gerber (método 497/IV; ZENEBON et al., 2008).

O teor de proteínas foi determinado pela técnica do destilador micro-Kjeldahl e do bloco digestor de acordo com o método 31.1.08 da AOAC (CUNNIFF, 1995). O valor de carboidrato foi obtido pela diferença dos valores encontrados para cinzas, umidade, lipídios e proteína em $100 \mathrm{~g}$ do produto (CUNNIFF, 1995). O pH foi determinado a partir de uma leitura direta e precisa com potenciômetro seguindo a recomendação do método 942.15 da AOAC (CUNNIFF, 1995). Por fim, para calcular o valor energético total, foram considerados os fatores de conversão de Atwater (WILSON et al., 1982) de $4 \mathrm{kcal} / \mathrm{g}$ de proteína, $4 \mathrm{kcal} / \mathrm{g}$ de carboidratos e $9 \mathrm{kcal} / \mathrm{g}$ de lipídios.

\section{Análise sensorial}

A avaliação sensorial das formulações de leite fermentado foi realizada no laboratório de Análise Sensorial do Departamento de Nutrição - UFPE/CAV. Para tal, foram avaliadas por um painel não treinado composto por 120 indivíduos, formados por docentes, técnicos administrativos e discentes da UFPE/CAV, ambos os sexos, com idade entre 18 e 50 anos, que previamente assinaram o Termo de Consentimento Livre e Esclarecido (TCLE), responderam a um questionário e em seguida foram submetidos ao teste sensorial afetivo, utilizando uma escala hedônica com nove pontos ancorados nos extremos: 9 para gostei muitíssimo a 1 desgostei muitíssimo. Concomitantemente foi realizado o teste de intenção de compra para avaliar a distribuição empírica das notas

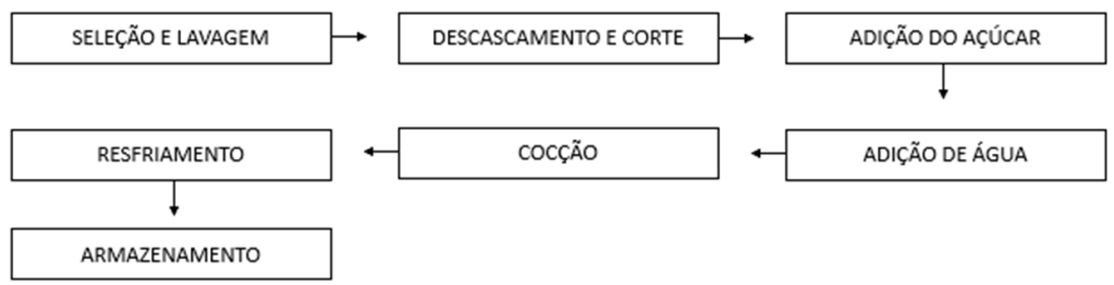

Figura 2 - Fluxograma representativo das etapas para obtenção do abacaxi em calda 
atribuídas ancoradas nas suas extremidades em 1 para "certamente compraria" e 5 para “certamente não compraria” (STONE; SIDEL, 1985). Os critérios de exclusão utilizados para selecionar os avaliadores foram: ser consumidor do produto e não apresentar intolerância ou alergia aos seus componentes.

\section{Análise estatística}

A análise físico-química e testes sensoriais foram submetidos à análise de variância (ANOVA) e posteriormente aplicouse o teste de Tukey $(\mathrm{p} \leq 0,05)$. As análises estatísticas foram realizadas utilizando-se o software BIOESTAT versão 5.3.

\section{RESULTADOS E DISCUSSÃO}

\section{Análise microbiológica}

De acordo com a legislação brasileira de padrões microbiológicos para alimentos - RDC n⿳0 12/2001 da ANVISA, os limites recomendados para leite fermentado são de $10 \mathrm{NMP} / \mathrm{g}$ para coliformes a $45^{\circ} \mathrm{C}$ e ausência de Salmonella sp. por $25 \mathrm{~g}$ de amostra. Sendo assim, os produtos elaborados estão adequados para o consumo humano na forma como se apresentam, assim como mostra a Tabela 2.

De acordo com Oliveira et al. (2013), que avaliaram vários lotes de leites fermentados de diferentes marcas, a ausência de coliformes na maioria dos lotes avaliados pode ser indicativa de boas condições higiênicosanitárias durante o processo de elaboração dos produtos. Portanto, com o resultado negativo para esse teste é possível concluir que os produtos estão aptos para o consumo e que foram tomadas todas as medidas de Boas Práticas de Fabricação (BPF).

\section{Análise físico-química}

Os valores obtidos a partir das análises físico-químicas realizadas em todas as formulações de leite fermentado estão representados na Tabela 3.

Observa-se que não há diferença estatística em relação ao pH para nenhuma das amostras analisadas. Nossos resultados diferem um pouco ao que a literatura científica apresenta, como a pesquisa de Medeiros et al. (2011) que, ao analisarem o $\mathrm{pH}$ em diferentes leites fermentados obtidos com diversos tipos de microrganismos, perceberam diferença entre as amostras, valores que variaram entre 3,68 a 4,23. Semelhante a este, Farias et al. (2012) avaliaram leites fermentados disponíveis no mercado e perceberam a variação de $\mathrm{pH}$ entre 3,60 a 4,11. Outro estudo mais recente comparou duas formulações

Tabela 2 - Análises microbiológicas de leites fermentados elaborados com abacaxi em calda em diferentes concentrações de leite de búfala e de vaca*

\begin{tabular}{ccc}
\hline Formulações & Coliformes $^{\circ}{ }^{\circ} \mathrm{C}$ & Salmonella sp. \\
\hline P & $<10 \mathrm{NMP} / \mathrm{g}$ & Ausente \\
F1 & $>10 \mathrm{NMP} / \mathrm{g}$ & Ausente \\
F2 & $>10 \mathrm{NMP} / \mathrm{g}$ & Ausente
\end{tabular}

P - Formulação Padrão com 100\% leite de vaca; F1 - Formulação 1 com 50\% de leite de búfala e 50\% de leite de vaca; F2 - Formulação com 100\% leite de búfala. UFC/g: Unidade Formadora de Colônia por grama.

* Valores expressos como $<10 \mathrm{NMP} / \mathrm{g}$ representam ausência de crescimento considerado limites do método, conforme a RDC $\mathrm{n}^{\circ} 12$ de 02 de janeiro de 2001 (BRASIL, 2001). 
distintas comercializadas em Minas Gerais e observaram diferenças nos valores de $\mathrm{pH}$, sendo um mais ácido que o outro, por apresentar menor valor de $\mathrm{pH}$ (OLIVEIRA et al., 2019). No entanto, os valores obtidos no presente estudo encontram-se dentro da faixa dos estudos supracitados.

Na produção de leites fermentados, um dos parâmetros utilizados para determinar quando a fermentação deve ser finalizada é a porcentagem de ácido lático, sendo determinado que o valor deve ser de no mínimo $0,60 \%$, para que haja inibição do crescimento de bactérias patogênicas ou deteriorantes que eventualmente estejam presentes no produto (BRASIL, 2007). Os resultados para acidez em ácido lático das formulações testadas neste estudo não apresentaram diferença entre si, no entanto, valores inferiores ao preconizado na literatura. Faria et al. (2006) analisaram leites de búfala fermentados com Lactobacillus casei em três diferentes tempos de fermentação (18, 22 e 24 h), onde observaram que o tempo de fermentação de 18 horas não foi suficiente para alcançar o valor recomendado $(0,18 \pm 0,02 \%, 0,63 \pm 0,01 \%$ e $0,67 \pm 0,02 \%$ de ácido lático, respectivamente). Assim, leva-se a crer que a variação da acidez é influenciada pelo tipo de cultura utilizada, a utilização de polpas ou caldas de frutas, e principalmente pelo tempo de fermentação, em menor proporção, pela temperatura.

A substituição do leite de búfala para elaborar produtos que tradicionalmente são derivados do leite de vaca pode ser pela factual comparação da qualidade nutricional e tecnológica destes. O leite de búfala, em relação ao de vaca, apresenta menor conteúdo de água e maior conteúdo de proteína, gordura e minerais (FAO, 1991; NASCIMENTO; CARVALHO, 1993). Sob essa ótica, observando os resultados da Tabela 3, percebe-se que as formulações que continham a proporção de 50 a $100 \%$ leite de búfala (F1 e F2) apresentaram valores superiores de proteínas, lipídeos e cinzas quando comparadas a formulação padrão composta $100 \%$ por leite de vaca. Embora não haja legislação específica com padrões para produtos derivados do leite de búfala (BRASIL, 2005), a bebida láctea deve apresentar no mínimo $2 \%$ de gordura e $1 \%$ de proteína, ambos de origem lática. Sendo assim, os valores médios para os tratamentos propostos apresentam-se dentro dos padrões permitidos pela legislação.

Tabela 3 - Resultado das análises físico-químicas das formulações de leite fermentado*

\begin{tabular}{lccc}
\hline \multicolumn{1}{c}{ Análises } & P & F1 & F2 \\
\hline $\mathrm{pH}$ & $4,3 \pm 0,03^{\mathrm{a}}$ & $4,1 \pm 0,02^{\mathrm{a}}$ & $4,3 \pm 0,03^{\mathrm{a}}$ \\
Acidez em ácido lático $(\mathrm{g} / 100 \mathrm{~g})$ & $0,5 \pm 0,02^{\mathrm{a}}$ & $0,5 \pm 0,03^{\mathrm{a}}$ & $0,5 \pm 0,02^{\mathrm{a}}$ \\
Proteína $(\mathrm{g} / 100 \mathrm{~g})$ & $4,2 \pm 0,01^{\mathrm{a}}$ & $4,6 \pm 0,05^{\mathrm{b}}$ & $4,7 \pm 0,01^{\mathrm{b}}$ \\
Lipídeos $(\mathrm{g} / 100 \mathrm{~g})$ & $8,0 \pm 0,01^{\mathrm{a}}$ & $9 \pm 0,01^{\mathrm{b}}$ & $10,0 \pm 0,01^{\mathrm{c}}$ \\
Cinzas $(\mathrm{g} / 100 \mathrm{~g})$ & $1,4 \pm 0,01^{\mathrm{a}}$ & $1,4 \pm 0,01^{\mathrm{a}}$ & $1,6 \pm 0,01^{\mathrm{b}}$ \\
Umidade $(\mathrm{g} / 100 \mathrm{~g})$ & $77,5 \pm 0,02^{\mathrm{a}}$ & $74,0 \pm 0,01^{\mathrm{b}}$ & $76,5 \pm 0,05^{\mathrm{a}}$ \\
Carboidratos $(\mathrm{g} / 100 \mathrm{~g})$ & $8,8^{\mathrm{a}}$ & $10,4^{\mathrm{b}}$ & $6,6^{\mathrm{c}}$ \\
\hline
\end{tabular}

Resultados expressos como média e desvio padrão. Letras diferentes na mesma linha indicam diferença significativa pelo teste de Tukey $(\mathrm{p}<0,05)$. P - Formulação Padrão com $100 \%$ leite de vaca; F1 - Formulação 1 com $50 \%$ de leite de búfala e $50 \%$ de leite de vaca; F2 - Formulação com $100 \%$ leite de búfala. 
Observando os valores de umidade na Tabela 3, nota-se que a formulação contendo $50 \%$ de ambos os leites apresentou diferença estatística comparada aos demais valores. No entanto, o LV se mostrou superior ao leite de búfala. Resultado semelhante também foi encontrado por Faria et al. (2006) quando comparou o LV com o LB $(87,82 \%$ e $86,53 \%$ de umidade, respectivamente). É cabível entender que o maior teor de umidade observado no LV é explicado pelo menor valor dos demais componentes do leite.

E, por fim, no que diz respeito aos valores de carboidratos, observa-se diferença estatística linear nas formulações, onde a F2 (100\% leite de búfala) apresentou o menor valor. A composição de carboidratos verificada neste trabalho aplicando a mesma metodologia de carboidrato por diferença (CUNNIFF, 1995), difere um pouco da pesquisa de Rojas et al. (2001) que utiliza leite de búfala integral para elaborar leite fermentado por Bifidobacterium bifidum e obtém 12,20 g/100 g de carboidrato. Já o trabalho Faria et al. (2006) utilizou leite de búfala desnatado fermentado por Lactobacillus casei e suplementado com Bifidobacterium longum e obteve valores superiores $(21,86 \%)$ do que os obtidos para o produto elaborado com leite de vaca. Quando submetido à fermentação, que depende do tipo de microrganismo utilizado, ocorrem modificações nos nutrientes, com o aumento da digestibilidade e da absorção de proteínas, lipídeos e carboidratos (FERREIRA, 1997; GOMES; MALCATA, 1999), podendo ser uma das possíveis explicações para os achados neste trabalho. Outra hipótese seria pelo fato da composição do leite, período de lactação, prática de ordenha, clima e nutrição das búfalas levar a diferenças na composição do leite (GUIMARÃES et al., 2015).

\section{Análise sensorial}

O perfil dos consumidores foi traçado baseado nos participantes da análise sensorial, onde foi possível observar que a maioria dos avaliadores foram do sexo feminino $(72,5 \%)$ e estavam entre a faixa etária de 18 e 30 anos $(96,6 \%)$, sendo, grande parte, estudantes do curso de Bacharelado em Nutrição (32,5\%). Os resultados de alguns estudos com o objetivo de conhecer os impactos da idade e do sexo sobre o paladar corroboram com o perfil encontrado neste trabalho. Esses estudos demonstraram que todos apresentaram um declínio considerável na percepção gustativa com o avançar da idade, sendo os jovens mais sensíveis aos sabores do que os idosos e, nos

Tabela 4 - Valores médios da análise sensorial afetiva em formulações de leite fermentado elaborados com abacaxi em calda em diferentes concentrações de leite de búfala e de vaca*

\begin{tabular}{lccc}
\hline Atributos & $\mathbf{P}$ & $\mathbf{F 1}$ & F2 \\
\hline Cor & $5,80 \pm 0,25^{\mathrm{c}}$ & $6,54 \pm 0,22^{\mathrm{b}}$ & $7,15 \pm 0,26^{\mathrm{a}}$ \\
Odor & $6,08 \pm 0,21^{\mathrm{b}}$ & $6,78 \pm 0,24^{\mathrm{a}}$ & $6,80 \pm 0,21^{\mathrm{a}}$ \\
Sabor & $4,95 \pm 0,17^{\mathrm{b}}$ & $6,56 \pm 0,24^{\mathrm{a}}$ & $6,59 \pm 0,23^{\mathrm{a}}$ \\
Textura & $4,85 \pm 0,14^{\mathrm{b}}$ & $6,19 \pm 0,21^{\mathrm{a}}$ & $6,33 \pm 0,24^{\mathrm{a}}$ \\
Aparência & $4,92 \pm 0,15^{\mathrm{b}}$ & $5,93 \pm 0,20^{\mathrm{a}}$ & $6,49 \pm 0,23^{\mathrm{a}}$ \\
\hline
\end{tabular}

* Resultados expressos como média e desvio padrão. Letras diferentes na mesma linha indicam diferença significativa pelo teste de Tukey $(\mathrm{p}<0,05)$. P - Formulação Padrão com 100\% leite de vaca; F1 - Formulação 1 com $50 \%$ de leite de búfala e $50 \%$ de leite de vaca; F2 - Formulação com $100 \%$ leite de búfala. 
testes de paladar, as mulheres apresentaram escores maiores comparados aos homens (LANDIS et al., 2009; PASSOS et al., 2016; SERGI et al., 2017; CHAMOUN et al., 2017).

A Tabela 4 expressa os valores em média obtidos a partir da análise sensorial realizada para avaliação das características sensoriais de cada formulação de leite fermentado.

Diante destes resultados é possível observar que para todas as formulações não houve diferença estatística $(\mathrm{p}<0,05)$, exceto para a Formulação Padrão (100\% leite de vaca), onde apresentou médias inferiores comparadas às demais.

No atributo cor do leite fermentado pode-se concluir que a formulação F2 (100\% leite de búfala), se difere das demais por ter sido atribuído a ela uma nota mais elevada $(7, .$.$) , se comparada às outras formulações.$ Isso pode ocorrer, segundo Teixeira et al. (2005), porque o leite bubalino é ausente de pigmentos carotenoides (precursor da vitamina A) responsável pela coloração mais amarelada no leite de vaca, proporcionando a este leite uma coloração totalmente branca, melhorando assim sua visibilidade (CENACHI et al., 2011). Outros estudos de análise sensorial revelam ainda que produtos lácteos, dentre eles leites fermentados, com a adição de frutas são bem aceitos, visto que a primeira impressão do consumidor sobre os alimentos está relacionada com a aparência visual (ROCHA et al., 2008; OLIVEIRA et al., 2008; GARCIA; TRAVASSOS, 2012; LINO et al., 2020).

Nos demais atributos (odor, sabor, textura e aparência) a formulação de leite fermentado $100 \%$ leite de vaca recebeu as menores médias, corroborando mais uma vez para a ideia de que o leite de búfala associado ao abacaxi em calda seria um produto lácteo bem aceito pelos consumidores devido a sua qualidade nutricional e funcional diferenciada, além das características positivas do ponto de vista físico-químico e organoléptico e sabor ligeiramente adocicado quando comparado ao leite de vaca (PATIÑO, 2011).

$\mathrm{Na}$ opinião dos avaliadores a formulação de leite fermentado com 100\% leite de búfala e abacaxi em calda foi a mais bem aceita, recebendo 59 votos ( $v s$. formulação $\mathrm{P}=16$ votos e $\mathrm{F} 1=45$ votos). Alguns fatores foram importantes para a maior aceitação da formulação com 100\% leite bubalino. O maior teor de sólidos presentes no leite de búfala influencia fortemente na consistência e, consequentemente, na aparência do produto (BORGES et al., 2009). O elevado teor de gordura presente no leite de búfala, confere uma característica palatável diferente das demais, o que pode explicar a aceitação dos consumidores para tal, assim como descrito por Thamer; Penna (2006).

Os elevados índices de aceitação do atributo sabor também podem apontar para a potencialidade do uso do abacaxi em calda, assim como na elaboração de outro produto lácteo como o iogurte com leite de bubalinos com calda de cajá em Borges e colaboradores (2009). De acordo com Anzaldúa-Morales (1994), o objetivo do teste de aceitação é estabelecer preferência por uma determinada amostra em detrimento de outra. Assim, sendo totalmente pessoal, a preferência pode ser influenciada tanto pela qualidade do alimento, quanto pela cultura do provador (MORAES, 1988). O abacaxi apresenta aspectos sensoriais peculiares, devido ao seu sabor e aroma característicos, que lhe são concedidos por diversos elementos químicos e pelo equilíbrio entre açúcares e ácidos orgânicos, sendo ainda uma fruta que se destaca pela presença de variados minerais (cálcio, fósforo, magnésio, potássio, sódio, cobre e iodo), enriquecendo ainda mais o produto elaborado (MATTA et al., 2010).

Em relação à intenção de compra, os provadores opinaram utilizando uma escala de cinco pontos anteriormente descrita, onde considerou valores mais próximos de 1 (certamente compraria) positivos para 
compra. A análise de intenção de compra do presente trabalho indicou que as formulações de leite fermentado compostas por $50 \%$ LV / 50\% LB e a formulação com $100 \%$ $\mathrm{LB}(\mathrm{F} 1=1,73 \pm 0,3$ e $\mathrm{F} 2=1,53 \pm 0,3, \mathrm{p}>0,05)$ não diferiram estatisticamente entre si, podendo ser perfeitamente comercializadas. Já a formulação Padrão com 100\% leite de vaca obteve média das notas acima de $2(2,68 \pm 0,1$ onde $\mathrm{p}<0,05$ comparada às demais formulações) mostrando que as notas atribuídas a ela variaram entre 2 (provavelmente compraria) e 3 (talvez compraria/talvez não compraria). Segundo Guerrero et al. (2000), a intenção de compra é um processo decisivo que leva em consideração vários fatores, como o preço, a conveniência e o marketing do produto, porém as características sensoriais são determinantes na decisão de compra. Assim, tais resultados conduzem aos fatores associados aos aspectos sensoriais do leite de búfala já citados e discutidos anteriormente.

O Manual de Rotulagem Nutricional da ANVISA (2005) que determina um valor energético médio para cada grupo de alimento, classifica os produtos elaborados como "Leites e derivados", determinando em uma porção
(100 g) o valor energético total de $125 \mathrm{kcal}$ ou $525 \mathrm{~kJ}$ (Quadro 1).

A rotulagem nutricional do leite fermentado obtido na formulação F2 (100\% leite de búfala) agrega ainda mais qualidade e valor ao produto elaborado, pois além das características sensoriais previamente aprovadas pelo painel sensorial, esta formulação também possui um baixo valor calórico, podendo ser inserido em uma alimentação mais saudável.

\section{CONCLUSÃO}

Todas as formulações apresentadas e testadas no presente trabalho estiveram de acordo com padrões microbiológicos exigidos pela legislação para leite fermentado, considerando-as um alimento seguro para o consumo humano. Pôde-se entrar em concordância com a literatura no que diz respeito aos aspectos físico-químicos dos produtos elaborados com o leite de búfala, bem como ocorreu similaridade entre as características da análise sensorial, apresentando valores satisfatórios para a formulação que apresentava exclusivamente o leite de búfala, mostrando que substituição total do

Quadro 1 - Informação nutricional correspondente a uma porção de leite fermentado da formulação F2 (100\% leite de búfala fermentado e abacaxi em calda)

\begin{tabular}{|l|c|c|}
\hline \multicolumn{3}{|c|}{$\begin{array}{c}\text { INFORMAÇÃO NUTRICIONAL } \\
\text { Porção de } 100 \mathrm{~g}(1 \text { porção })\end{array}$} \\
\hline \multicolumn{2}{|c|}{ Quantidade por porção } & $\% \mathrm{VD}(*)$ \\
\hline Valor calórico & $135 \mathrm{kcal}=568 \mathrm{~kJ}$ & $2 \%$ \\
\hline Carboidratos & $6,6 \mathrm{~g}(26,4 \mathrm{kcal})$ & $6 \%$ \\
\hline Proteínas & $4,7 \mathrm{~g}(18,8 \mathrm{kcal})$ & $18 \%$ \\
\hline Gorduras totais & $10 \mathrm{~g}(90,0 \mathrm{kcal})$ & $\mathrm{kJ}$. \\
\hline \begin{tabular}{l} 
(*) \% Valores diários de referência com base em uma dieta de $2000 \mathrm{kcal}$ ou $8400 \mathrm{~kJ}$. \\
Seus valores diários podem ser maiores ou menores dependendo de suas necessidades \\
\hline
\end{tabular} \\
\hline
\end{tabular}


leite de vaca não interferiu na aceitabilidade do produto.

Os resultados obtidos permitiram mostrar que é viável a produção da bebida láctea fermentada utilizando $100 \%$ de leite de búfala em sua formulação como matéria prima. Além disso, a adição do abacaxi em calda confere maior valor nutritivo à bebida láctea e ao mesmo tempo contribuindo para a economia regional, promovendo a valorização das frutas da região, se apresentando como um produto com potencial de comercialização e diversificação na produção leiteira de búfala.

Diante disso, os dados obtidos no presente trabalho podem vir a ser aplicados na indústria de tecnologia alimentícia, com o intuito de oferecer aos consumidores um novo produto com vários benefícios a saúde, além de poder ser aplicado em lanches de cardápio de unidades de alimentação e nutrição.

\section{REFERÊNCIAS}

ANDRADE, K. D. et al. Efeito da estação do ano na qualidade do leite de búfalas. Revista Verde de Agroecologia e Desenvolvimento Sustentável, v. 6, n. 3, p. 33-37, 2011.

ANDRIGHETTO, C. Cadeia produtiva do leite de búfala: Visão da universidade. In: SIMPÓSIO DA CADEIA PRODUTIVA DA BUBALINOCULTURA, 2.; INTERNATIONAL SYMPOSIUM OF BUFFALO PRODUCTION CHAIN, 1., 2011, Botucatu. Anais [...]. Botucatu: FEPAF, 2011.

ANVISA - AGÊNCIA NACIONAL DE VIGILÂNCIA SANITÁRIA; UnB UNIVERSIDADE DE BRASÍLIA. Rotulagem Nutricional Obrigatória: Manual de Orientação às Indústrias de Alimentos. 2. versão. Brasília: ANVISA, UnB, 2005. 44 p.

ANZALDÚA-MORALES, A. La evaluación sensorial de los alimentos en la teoría y la prática. Zaragoza: Acribia, 1994. 214 p.

BERNARDES, O. Bubalinocultura no Brasil: Situação e importância econômica. Revista Brasileira de Reprodução Animal, v. 31, n. 3, p. 293-298, 2007.

BORGES, K. C.; MEDEIROS, A. C. L.; CORREIA, R. T. P. Iogurte de leite de búfala sabor cajá (Spondias lutea L.): Caracterização físico-química e aceitação sensorial entre indivíduos de 11 a 16 anos. Alimentos e Nutrição, v. 20, n. 2, p. 295-300, 2009.

BRASIL. Ministério da Agricultura, Pecuária e Abastecimento. Instrução Normativa $n^{\circ} 46$, de 23 de outubro de 2007. Regulamento técnico de produção, identidade e qualidade de leites fermentados. Diário Oficial da União: seção 1, Brasília, DF, n. 205, p. 4, 24 out. 2007.

BRASIL. Ministério da Agricultura, Pecuária e Abastecimento. Regulamento Técnico de Identidade e Qualidade de Bebida Láctea. Instrução Normativa $n^{\circ} 16$, de 23 de agosto de 2005. Diário Oficial da União, Seção 1, p. 7. Brasília, 24 de agosto 2005 .

BRASIL. Ministério da Saúde. Agência Nacional de Vigilância Sanitária. Resolução RDC n ${ }^{\circ} 12$, de 2 de janeiro de 2001. Aprova o Regulamento Técnico sobre Padrões Microbiológicos para Alimentos. Diário Oficial da União: seção 1, Brasília, DF, n. 7, p. 45,10 jan. 2001 .

CENACHI, D. B. et al. Aspectos composicionais, propriedades funcionais, nutricionais e sensoriais do leite de cabra: Uma revisão. Revista do Instituto de Laticínios Cândido Tostes, v. 66, n. 382, p. 12-20, 2011. CHAMOUN, E. et al. A review of the associations between single nucleotide 
polymorphisms in taste receptors, eating behaviors, and health. Journal Critical Reviews in Food Science and Nutrition, v. 58, n. 2, p. 194-207, 2017. DOI: 10.1080/10408398.2016.1152229.

COELHO, A. S. Cenário da bubalinocultura no Brasil. Trabalho de Conclusão de Curso (Graduação em Medicina Veterinária) Universidade Federal Rural da Amazônia, Campus Belém, PA, 2019.

CUNNIFF, P. A. (ed.). Official methods of analysis of AOAC International. 16th ed. Arlington: AOAC International, 1995.

FAO - FOOD AND AGRICULTURE ORGANIZATION OF THE UNITED NATIONS. Animal Production and Health Division (AGA): Production, 2013. Disponível em: http://www.fao.org/statistics/ en/. Acesso em: 4 maio 2020.

FAO - FOOD AND AGRICULTURE ORGANIZATION OF THE UNITED NATIONS. O Búfalo. Brasília: Ministério da Agricultura; São Paulo: Associação Brasileira dos Criadores de Búfalo, 1991. 320 p. (FAO Produção Animal e Saúde, 4.).

FARIA, C. P.; BENEDET, H. D.; LE GUERROUE, J. L. Parâmetros de produção de leite de búfala fermentado por Lactobacillus casei Pesquisa Agropecuária Brasileira, v. 41 , n. 3, p. 511-516, 2006. DOI: $10.1590 /$ S0100-204X2006000300019.

FARIAS, M. M. A. G. et al. Avaliação da acidez de diversas marcas de leite fermentado disponíveis comercialmente. Pesquisa Brasileira em Odontopediatria e Clínica Integrada, v. 12, n. 4, p. 451-455, 2012. DOI: 10.4034/PBOCI.2012.124.01.

FERREIRA, C. L. L. F. Valor nutricional e bioterapêutico de leites fermentados. Leite $\boldsymbol{\&}$ Derivados, v. 6, n. 36, p. 46-52, 1997.

FIGUEIREDO, E. L.; LOURENÇO JÚNIOR, J. B.; TORO, M. J. U. Caracterização físicoquímica e microbiológica do leite de búfala "in natura" produzido no estado do Pará. Revista Brasileira de Tecnologia Agroindustrial, v. 4, n. 1, p. 19-28, 2010. DOI: 0.3895/S198136862010000100003 .

GARCIA, R. V.; TRAVASSOS, A. E. R. Leite fermentado caprino sabor umbu: Elaboração e aceitabilidade. Revista do Instituto Adolfo Lutz, v. 71, n. 1, p. 134-139, 2012.

GOMES, A. M. P.; MALCATA, F. X. Bifidobacterium spp. and Lactobacillus acidophilus: Biological, biochemical, technological and therapeutical properties relevant for use as probiotics. Trends in Food Science and Technology, v. 10, n. 4-5, p. 139-157, 1999. DOI: 10.1016/ S0924-2244(99)00033-3.

GUERRERO, J. A. et al. Particle positioning from CCD images: Experiments and comparison with the generalized LorenzMie theory. Measurement Science and Technology, v. 11, n. 5, p. 568-575, 2000. DOI: $10.1088 / 0957-0233 / 11 / 5 / 318$.

GUIMARÃES, D. H. P.; SILVA, F. R. S. R.; LÊNTHOLA, N. M. Iogurte elaborado à base de leite de búfala sabor queijo com geleia de goiaba. Brazilian Journal of Food Technology, v. 18, n. 1, p. 57-61, 2015. DOI: 10.1590/1981-6723.4114.

LANDIS, B. N. et al. "Taste Strips" - A rapid, lateralized, gustatory bedside identification test based on impregnated filter papers. Journal of Neurology, v. 256, p. 242-248, 2009. DOI: $10.1007 / \mathrm{s} 00415-009-0088-y$. LINO, D. L. et al. Desenvolvimento e 
análise sensorial de bebida láctea de jamelão. Alimentos: Ciência, Tecnologia e Meio Ambiente. v. 1, n. 4, P. 63-77, 2020.

MACEDO, M. P. et al. Composição físicoquímica e produção do leite de búfalas da raça Mediterrâneo no oeste do estado de São Paulo. Revista Brasileira de Zootecnia, v. 30, n. 3, p. 1084-1088, 2001. DOI: 10.1590/ S1516-35982001000400024.

MARINHO, M. V. M. et al. Análise físicoquímica e sensorial de iogurte de leite de cabra com polpa de umbu. Revista Brasileira de Produtos Agroindustriais, v. 14, n. esp., p. 497-510, 2012.

MATOS, A. P. et al. A cultura do abacaxi. 2. ed. rev. e ampl. Brasília: Embrapa Informação Tecnológica, 2006. (Coleção Plantar, 49).

MATTA, V. M. et al. Desenvolvimento de compota de abacaxi em calda de melado. Rio de Janeiro: Embrapa Agroindústria de Alimentos, 2010. (Comunicado Técnico, 175).

MAZIERO, M. T.; TOLENTINO, M. C.; WASZCZYNSKYJ, N. Propriedades sensoriais e físico-químicas de leites fermentados comerciais. Revista Brasileira de Tecnologia Agroindustrial, v. 5, n. 1, p. 274-281, 2011. DOI: 10.3895/S198136862011000100003 .

MEDEIROS, E. J. L. et al. Leite fermentado de marcas comerciais: estudo da aceitação e correlação com ph e acidez. Revista do Instituto de Laticínios Cândido Tostes, v. 66, n. 381, p. 46-51, 2011.

MODESTO JÚNIOR, E. N. et al. Elaboração de iogurte grego de leite de búfala e influência da adição de calda de ginja (Eugenia uniflora L.) no teor de ácido ascórbico e antocianinas do produto. Revista do Instituto de Laticínios
Cândido Tostes, v. 71, n. 3, p. 131-143, 2016. DOI: $10.14295 / 2238-6416 . v 71 i 3.523$.

MORAES, M. A. C. Métodos para avaliação sensorial dos alimentos. 6. ed. Campinas: Editora da Unicamp, 1988. 93 p.

NASCIMENTO, C.; CARVALHO, L.O.M. Criação de búfalos: Alimentação, manejo, melhoramento e instalações. Brasília: Embrapa-SPI, 1993. 403 p.

OLIVEIRA, C. D. et al. Avaliação físicoquímica de leites fermentados comercializados em Diamantina - MG. Brazilian Applied Science Review, v. 3, n. 1, p. 343-348, 2019.

OLIVEIRA, F. M.; LYRA, I. N.; ESTEVES, G. S. G. Avaliação microbiológica e físico-química de iogurtes de morango industrializados e comercializados no município de Linhares - ES. Revista Brasileira de Produtos Agroindustriais, v. 15, n. 2, p. $147-155,2013$.

OLIVEIRA, K. A. M. et al. Desenvolvimento de formulação de iogurte de araticum e estudo da aceitação sensorial. Revista Alimentos e Nutrição, v. 9, n. 3, p. 277-81, 2008.

OLIVEIRA, P. D. et al. Avaliação sensorial de iogurte de açaí (Euterpe oleracea Mart.) tipo "sundae". Revista do Instituto de Laticínios Cândido Tostes, v. 66, n. 380, p. 5-10, 2011.

PASSOS, J. G.; GUIMARÃES, L. C.; VICTORIA, M. C. M. Avaliação da percepção gustativa em idosos para os gostos básicos, doce e salgado, em comparação a jovens adultos. Journal of the Health Sciences Institute, v. 34, n. 1, p. 29-32, 2016.

PATIÑNO, E. M. Producción y calidad de la leche bubalina. Tecnología en Marcha, v. 24, n. 5, Revista Especial, p. 25-35, 2011. 
ROCHA, C. et al. Elaboração e avaliação de iogurte sabor frutos do cerrado. Boletim do Centro de Pesquisa e Processamento de Alimentos, v. 26, n. 2, p. 255-266, 2008.

ROJAS, C. A. et al. Desarrollo de una leche fermentada a partir de leche de búfala con adición de Bifidobacterium bifidum. Alimentaria: Revista de Tecnología e Higiene de los Alimentos, v. 38, n. 327, p. 97-100, 2001.

SEBRAE. O cultivo e o mercado do abacaxi. 2016. Disponível em: https://www.sebrae. com.br/sites/PortalSebrae/artigos/o-cultivoe-o-mercado-do-abacaxi,71b3438af1c9241 0VgnVCM100000b272010aRCRD. Acesso em: 2 maio 2019.

SERGI, G. et al. Taste loss in the elderly: Possible implications for dietary habits. Journal Critical Reviews in Food Science and Nutrition, v. 57 , n. 17 , p. 3684-3689, 2017. DOI: $10.1080 / 10408398.2016 .1160208$.

STONE, H.; SIDEL, J. L. Sensory evaluation practices. San Diego: Academic Press, 1985. $311 \mathrm{p}$.

TEIXEIRA, L. V.; BASTIANETTO, E.;
OLIVEIRA, D. A. A. Leite de búfala na indústria de produtos lácteos. Revista Brasileira de Reprodução Animal, v. 29, n. 2, p. 96-100, 2005.

THAMER, K.; PENNA, A. Caracterização de bebidas lácteas funcionais fermentadas por probióticos e acrescidas de prebiótico. Ciência e Tecnologia de Alimentos, v. 26, n. 3 , p. $589-595,2006$. DOI: $10.1590 / \mathrm{S} 0101-$ 20612006000300017

VIEIRA, E. T. V.; ITAVO, L. C. V.; ARANHA, J. A. M. Ponto de equilíbrio contábil na pecuária leiteira de bubalinos: Um estudo de caso da viabilidade econômico-financeira em uma propriedade do estado de Mato Grosso do Sul. Revista Científica Hermes, v. 21, p. 364-379, 2018

WILSON, E. D.; SANTOS, A. C.; VIEIRA, E. C. Energia. In: OLIVEIRA, J. E. D.; SANTOS, A. C.; WILSON, E. D. (Coords.). Nutrição básica. São Paulo: Sarvier, 1982.

ZENEBON, O.; PASCUET, N. S.; TIGLEA, P. (coord.). Métodos físico-químicos para análise de alimentos. 4. ed., 1. ed. digital. São Paulo: Instituto Adolfo Lutz, 2008.1020 p. 